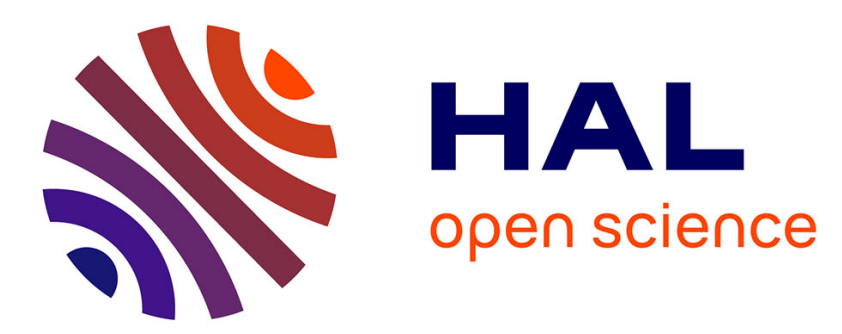

\title{
Formation and characterization of emulsions consisting of dense carbon dioxide and water: Ultrasound
}

\author{
Michael T. Timko, Samuel Marre, Alex R. Maag
}

\section{To cite this version:}

Michael T. Timko, Samuel Marre, Alex R. Maag. Formation and characterization of emulsions consisting of dense carbon dioxide and water: Ultrasound. Journal of Supercritical Fluids, 2016, 109, pp.51-60. 10.1016/j.supflu.2015.10.028 . hal-01254587

\section{HAL Id: hal-01254587 \\ https://hal.science/hal-01254587}

Submitted on 13 Jan 2021

HAL is a multi-disciplinary open access archive for the deposit and dissemination of scientific research documents, whether they are published or not. The documents may come from teaching and research institutions in France or abroad, or from public or private research centers.
L'archive ouverte pluridisciplinaire HAL, est destinée au dépôt et à la diffusion de documents scientifiques de niveau recherche, publiés ou non, émanant des établissements d'enseignement et de recherche français ou étrangers, des laboratoires publics ou privés. 


\title{
Formation and characterization of emulsions consisting of dense carbon dioxide and water: Ultrasound
}

\author{
Michael T. Timko ${ }^{\mathrm{a}, *}$, Samuel Marre ${ }^{\mathrm{b}}$, Alex R. Maag ${ }^{\mathrm{a}}$ \\ a Department of Chemical Engineering, Worcester Polytechnic Institute (WPI), 100 Institute Road, Worcester, MA 01609, USA \\ b Supercritical Fluids Group, CNRS, University Bordeaux, ICMCB, F-33600 Pessac, France
}

Keywords:

Supercritical carbon dioxide

Ultrasound

Emulsion

Cavitation

\begin{abstract}
A B S T R A C T
In this work, we studied ultrasound formation of surfactant-free emulsions consisting of water and dense carbon dioxide $\left(\mathrm{CO}_{2}\right)$. Emulsions with limited kinetic stability were formed after approximately 2 min of pulsed ultrasound at $20 \mathrm{kHz}$ and above a critical power density of at least $0.05 \mathrm{~W} \mathrm{~cm}^{-3}$. Emulsion stability and formation were studied using a variety of techniques. In situ microscopy using a highpressure microfluidic reactor indicated that the water $/ \mathrm{CO}_{2}$ emulsion consisted of finer droplets of about $5 \mu \mathrm{m}$ compared to the $\mathrm{CO}_{2} /$ water emulsion which consisted of droplets with average diameters of about $12 \mu \mathrm{m}$. A partially miscible tracer technique was used to measure the dispersed phase content of the two emulsions to be about $4 \mathrm{vol} \%$ and up to $9 \mathrm{vol} \%$ for the $\mathrm{CO}_{2} /$ water and water $/ \mathrm{CO}_{2}$ emulsions, respectively. Engineering analysis and complementary experiments indicated that the water $/ \mathrm{CO}_{2}$ emulsions formed via a two-step mechanism consisting of surface wave break-up to form a coarse emulsion followed by cavitation to form a fine emulsion. We use KI oxidation as a probe reaction to examine ultrasound-induced chemistry in the dense $\mathrm{CO}_{2}$ /water system, finding that $\mathrm{KI}$ oxidation was suppressed by the presence of a high pressure $\mathrm{CO}_{2}$ phase. Through the combination of formation, stability, and KI oxidation experiments and analyses, we suggest that the dense $\mathrm{CO}_{2}$ cushioned cavitation bubble collapse, damping ultrasound chemical effects while permitting physical effects such as emulsification. Engineering analysis suggests energy efficient scale-up might be achieved in a carefully designed flow reactor.
\end{abstract}

\section{Notation}

$\left\langle d_{N}\right\rangle$

$\left\langle d_{S}\right\rangle$

$\left\langle d_{V}\right\rangle$

$\left\langle d_{32}\right\rangle$

$L$

settling path length

$r \quad$ droplet radius

g gravitational constant $\left(9.8 \mathrm{~m} \mathrm{~s}^{-2}\right.$ at sea level)

$U_{\text {unhindered }}$ unhindered settling velocity, used for dilute emulsions

$U_{\text {hindered }}$ hindered settling velocity, used for concentrated emulsions

$\tau_{\text {observed }}$ observed time required for emulsion breaking

$\tau_{\text {unhindered }}$ calculated time required for emulsion breaking by unhindered settling

\footnotetext{
* Corresponding author. Tel.: +1 508831 4101; fax: +1 5088315774. E-mail address: mttimko@wpi.edu (M.T. Timko).
}

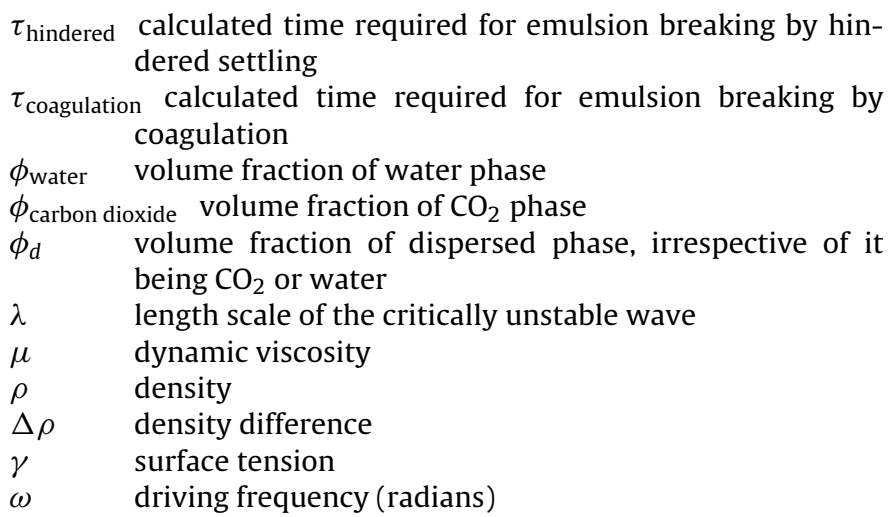

\section{Introduction}

Homogeneous catalysis has potential advantages over the heterogeneous variety for many applications yet its potential has not yet fully been recognized due to challenges in the design of industrial-scale chemical reactors employing homogeneous 
catalysts [1-3]. Catalyst retention, recovery, and reuse is the source of most failed attempts at commercialization [1]. Use of homogeneous catalysts under biphasic conditions [4], in which separate, immiscible phases are used for different reaction, separations, and catalyst applications, has been shown as an attractive approach in synthetic chemistry [4], commodity chemicals [5], and fuels [6] applications.

A chief consideration in biphasic reaction design is selection of the immiscible solvents; careful selection can benefit product yields and selectivity [7]. In addition to performance considerations, environmental and process considerations must be factored into the decision. For this reason, biphasic reaction mixtures consisting of water and a supercritical fluid (SCF) have substantial promise [8-11]. At conditions typical of process chemistry (25-350 ${ }^{\circ} \mathrm{C}$ and $\left.0.1-20 \mathrm{MPa}\right)$, many commonly used SCFs, including $\mathrm{CO}_{2}$ [12], ethane, and propane are immiscible with water-an obvious requirement for biphasic reactions. Near the critical point, modest changes in operating conditions can be used to tune physiochemical properties [13], including diffusion coefficients [14-16], viscosity, partition coefficients [17-19], and even aqueous phase $\mathrm{pH}$ within a modest range $[20,21]$. Additionally, the use of SCFs such as $\mathrm{scCO}_{2}$ provides means for easy catalyst separation and product recovery by depressurization without requirement for further processing steps.

When $\mathrm{CO}_{2}$ is selected as the SCF in conjunction with water, both solvents in the biphasic system are environmentally benign, non-toxic, inexpensive, and abundant. In fact, $\mathrm{scCO}_{2}$-water mixtures as both emulsions [22-31] and microemulsions [32] have been used for a wide variety of chemical reactions including Diels-Alder cycloaddition [33], olefin epoxidation [34], hydrolysis reactions [35-37], polymerization reactions [38], Barbier reaction [39], oxidation [40], hydrogenation [41,42], hydroformylation [43], biomass pretreatment [44], hydrogen peroxide synthesis [45,46], and particle and materials synthesis [47]. Beyond the chemical process industries, $\mathrm{scCO}_{2}$ /water mixtures - including emulsions - are likely important in geological systems and potentially of interest for geological $\mathrm{CO}_{2}$ sequestration and $\mathrm{CO}_{2}$ enhanced oil recovery [48].

Finite mass transfer rates are a challenge that can limit efficiency in biphasic reaction mixtures, especially for rapid chemical reactions $[35,36]$. Increasing the mixing rate and $\mathrm{scCO}_{2}$-water interfacial area, either as microemulsions or emulsions, is an effective strategy for overcoming mass transfer limitations [33]. For process efficiency, the energy costs of surface area generation can be an important consideration. The use of surfactants may decrease the energy required to generate surface area, and surfactant addition can be a viable economic option in some cases.

Unfortunately, use of surfactants incurs additional environmental and economic costs associated with surfactant synthesis, recovery, and reuse. The costs are especially problematic for surfactant-stabilized water-scCO $\mathrm{CO}_{2}$ biphasic mixtures as these have required boutique or highly fluorinated surfactants [49]. The costs of fluorinated surfactants suggests a search for surfactant-free emulsions [50] consisting of water and $\mathrm{scCO}_{2}$ phases.

Ultrasound has been demonstrated to be an additive-free method to generate short-lived emulsions consisting of water and $\mathrm{scCO}_{2}[33,35,36,51]$ or to improve the effectiveness of low-cost hydrocarbon surfactants stabilizing water and $\mathrm{scCO}_{2}$ emulsions. Timko et al. [36] found that short-lived, surfactant-free emulsions could be generated consisting of $\mathrm{scCO}_{2}$ and water and used them for hydrolysis [35] and Diels-Alder reactions [33]. More recently, Cenci et al. [37,39] used pulsed ultrasound to generate water-scCO emulsions, studied their stability, and used them for a hydrolysis [37] and Barbier reactions [39]. In addition to surfactant-free emulsions, Cenci et al. investigated the use of an inexpensive hydrocarbon surfactant, Tween 80 , to increase the volume fraction of
$\mathrm{scCO}_{2}$ dispersed in the water phase from approximately $5 \%$ to $35 \%$ and to extend the apparent breaking time from $15 \mathrm{~min}$ to $60 \mathrm{~min}$.

These two sets of ultrasound studies [18,33,35-37,39,51] indicate the potential for ultrasound to generate emulsions consisting of water and $\mathrm{scCO}_{2}$ phases. Unfortunately, characteristics of emulsions consisting of water and dense $\mathrm{CO}_{2}$ phases have been incompletely published, the mechanism of ultrasound formation of water- $\mathrm{scCO}_{2}$ emulsions is not fully understood, and the energy and scale-up requirements are poorly understood. Here, we present new data and analysis to examine the emulsification mechanism of power ultrasound of $\mathrm{CO}_{2}$-water mixtures. The focus is on ultrasound emulsification process in a batch reactor and we present new data on the emulsion volume fractions, droplet distributions, and stability. We couple this with experiments and analysis of cavitation and surface wave formation. These contributions advance the state of knowledge of emulsification of dense $\mathrm{CO}_{2}$-water mixtures and provide an engineering basis for reactor design.

\section{Experiment}

\subsection{Experimental system}

The complete experimental system consisted of a high-pressure ultrasonic reactor, used to generate the emulsions, and a highpressure microfluidic reactor, used to image emulsion droplets. The Supporting Information contains a simple schematic of the complete system.

\subsection{Ultrasonic reactor}

The high-pressure ultrasonic reactor used in this work was described previously in the literature [35,51] and only the most relevant details are provided here. The main body of the reactor was a 316-stainless steel block. Into this block, were bored two cylinders that intersected (diameter $=1.9 \mathrm{~cm}$ ) at the center of the block. A titanium probe (o.d. $=0.80 \mathrm{~cm}$ ) was sealed into one of the 4 main reactor openings so that the tip of the probe was approximately $1 \mathrm{~cm}$ offset from the intersection point. The other 3 reactor openings were sealed using $\alpha-\mathrm{Al}_{2} \mathrm{O}_{3}$ (sapphire) windows and stainless steel glands. Additional entry ports were machined into the reactor to measure pressure and temperature. With all ports sealed, the reactor volume was $87.2 \pm 0.4 \mathrm{~cm}^{3}$ and, except where noted, the reactor was filled $50 / 50 \mathrm{vol} / \mathrm{vol}$ with water and $\mathrm{CO}_{2}$ during all experiments.

\subsection{Emulsion imaging}

The stability of ultrasonically formed emulsions was determined visually by recording the time required for the emulsion to clear after ultrasound had been terminated. A video camera (Sanyo, VCB 3524) equipped with telescopic lenses (Tiffen) was used to record images. The camera was focused on the center of the reactor, which corresponded to a working distance of roughly $7 \mathrm{~cm}$. A fiber optic light source (Fostec, 8375) with a maximum power output of $150 \mathrm{~W}$ provided indirect lighting by reflection off a PTFE sheet placed behind the reactor. A standard video recorder was used to archive demulsification. The video tape was digitized using commercial software (FinalCut) and still images were extracted from the digitized movies.

\subsection{Volume fraction measurement}

A chemical tracer technique was used to measure dispersed phase volume fractions [35]. A known quantity of tracer was added to the reactor before filling with $\mathrm{CO}_{2}$ and water. To take advantage of near-quantitative partitioning in the desired phase, octane 
was used as a tracer for $\mathrm{CO}_{2}$ and $\mathrm{KNO}_{3}$ as a tracer for water. The reactor contents were allowed to equilibrate for 30-60 min under conditions of gentle stirring and then subjected to power ultrasound $(20 \mathrm{kHz}, 25 \%$ duty for a $1 \mathrm{~s}$ cycle). Emulsion samples of known volume $\left(0.47 \mathrm{~cm}^{3}\right)$ were extracted and de-pressurized into a small volume of solvent before their composition was analyzed using ion chromatography $\left(\mathrm{KNO}_{3}\right)$ or gas chromatography (octane). The measured concentrations were then related back to the dispersed phase volume fractions (either $\phi_{\text {water }}$ or $\phi_{\text {carbon dioxide }}$ ) by simple mass balance.

\subsection{Droplet imaging}

The $\mathrm{CO}_{2}$-water mixtures contained within the high-pressure reactor were too dense for optical characterization and the path length was deemed too long to avoid multiple scattering events that would introduce error into light scattering analysis. To overcome these challenges for direct imaging of emulsion droplets, we used a silicon/Pyrex microfluidic reactor [52-55] allowing for easy optical access while providing the ability to sustain high pressures. The body of the microreactor was a silicon chip that was etched with a $0.2 \mathrm{~m}$ long, $625 \mu \mathrm{m}$ wide and $250 \mu \mathrm{m}$ deep channel. An aluminum mount provided mechanical stability. A photograph of the microfluidic reactor assembly is included in the Supporting Information.

Emulsions were formed using power ultrasound $\left(0.6 \mathrm{~W} \mathrm{~cm}^{-3}\right.$, $20 \mathrm{kHz}, 2$ min sonication, $25 \%$ duty of a $1 \mathrm{~s}$ cycle). After ultrasound was terminated, a high-pressure pump (Milton Roy) was used to withdraw samples from the reactor into the microfluidic reactor. Emulsion was allowed to flow for approximately $10 \mathrm{~s}$ to ensure that a representative sample had been captured. Then, flow was terminated and the emulsion droplets inside the microfluidic reactor were sized using an inverted microscope (Zeiss Axiovert 200). Polystyrene latex microspheres, ranging in diameter from 4 to $20 \mu \mathrm{m}$, were used to verify the microscope size calibration.

\subsection{KI oxidation experiments}

KI oxidation experiments were performed in the ultrasound reactor under nitrogen and carbon dioxide atmospheres. The reactor was filled with $60 \mathrm{~cm}^{3}$ of an aqueous solution containing $0.5 \mathrm{~mol} \mathrm{~L}^{-1}$ ( $8 \mathrm{wt} \%$ ) of potassium iodide. The head space of the reactor was purged of atmospheric gas by either nitrogen or carbon dioxide. The reactor was pressurized (if desired); heated to the set temperature; and sonicated at a power density of $1.0 \mathrm{~W} \mathrm{~cm}^{-3}$ and $20 \mathrm{kHz}$. Samples were extracted at regular time intervals using a HPLC valve (Valco Instrument Company, Inc.) and analyzed for $I_{3}^{-}$with visible absorption spectroscopy (Varian, Cary 50) using its $354 \mathrm{~nm}$ peak. Standard solutions of aqueous iodine corresponded to a molar extinction coefficient (at $\lambda=354 \mathrm{~nm}$ ) of $6000 \mathrm{~L} \mathrm{~mol}^{-1} \mathrm{~cm}^{-1}$.

\section{Results}

The aims of this study were: to characterize ultrasound emulsions consisting of dense carbon dioxide; to investigate the formation mechanisms of the ultrasound emulsions; and to examine the engineering implications. The results are divided accordingly: Sections 3.1-3.3 focus on emulsion characterization and emulsion stability analysis; Sections 3.4-3.6 describe experiments and analysis to investigate ultrasound formation mechanisms; Section 4 concludes with a discussion of engineering implications pertaining to scale-up and energy efficiency.

Sonication of $\mathrm{CO}_{2}-\mathrm{H}_{2} \mathrm{O}$ mixtures leads to simultaneous formation of $\mathrm{CO}_{2}$-continuous and water-continuous emulsions. For nomenclature, we adopt the "dispersed/continuous" convention to list the dispersed phase first and the continuous phase second. Hence, a $\mathrm{CO}_{2} /$ water emulsion consists of $\mathrm{CO}_{2}$ droplets in an water continuous phase-and vice versa. In cases where we do not imply an emulsion, we use the generic convention "carbon dioxidewater" to denote a mixture consisting of these two components with no indication of the state of dispersion.

\subsection{Bulk emulsion characterization}

Experiments were performed to measure emulsion stability and dispersed phase volume fractions. After preliminary experiments with continuous sonication, all experiments were performed with pulsed ultrasound, except where noted otherwise. After 10 s sonication, the emulsions became visually turbid and ultrasound was continued for 2 min to ensure that the system had reached steady state. Fig. 1 provides still images of the carbon dioxide-water emulsions as a function of time after ultrasound termination. In all cases and at all times, the emulsions were turbid and gray in color. The experiment was performed over a range of ultrasound power densities and the times required to break the upper (carbon dioxide continuous) and lower (water continuous) emulsion were recorded $\left(\tau_{\text {observed }}\right)$. Table 1 provides a summary of the resulting values for $\tau_{\text {observed }}$, with uncertainties of \pm 2 min or $\pm 20 \%$, whichever was less. Here, $\tau_{\text {observed }}$ was defined as the time required for the emulsion turbidity to decrease to $<10 \%$ of its value after termination of ultrasound [36].

Experiments were performed at two conditions: (1) 65 bar at $25^{\circ} \mathrm{C}$ and (2) $80 \mathrm{bar}$ at $30^{\circ} \mathrm{C}$. We selected these conditions to maintain a similar difference between reactor pressure and $\mathrm{CO}_{2}$ saturation pressure, while maintaining a liquid-like $\mathrm{CO}_{2}$ density of $0.70 \mathrm{~g} \mathrm{~cm}^{-3}$ [56]. A threshold ultrasound power density was required to generate both types of emulsions. Increases in power density beyond the threshold led to modest increases in $\tau_{\text {observed }}$. Interestingly, $\tau_{\text {observed }}$ for the $\mathrm{CO}_{2} /$ water emulsions increased from about $5 \mathrm{~min}$ when the emulsion was formed at 65 bar to 15 min when the pressure was increased to 80 bar. Emulsions persisted for several hours (the duration of the experiment), when

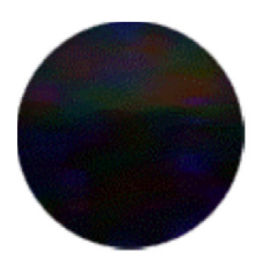

(a)

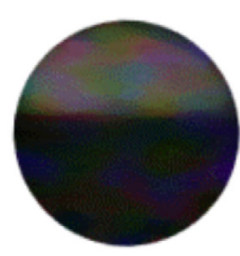

(b)

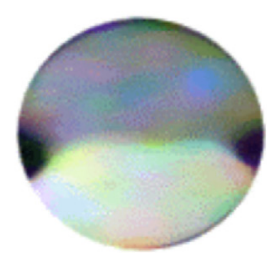

(c)

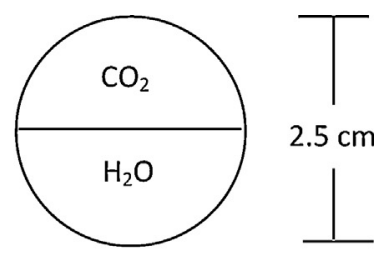

(d)

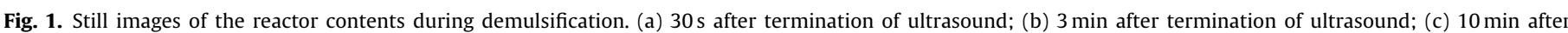

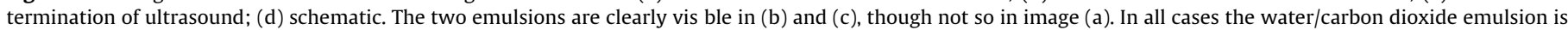

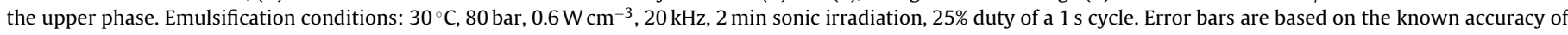
the trace analysis techniques. 

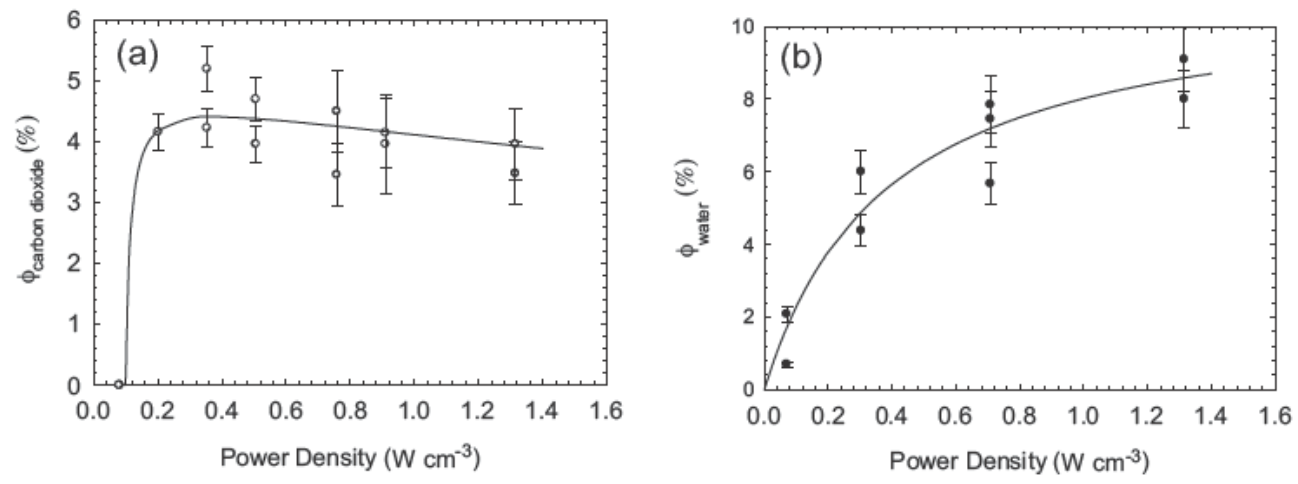

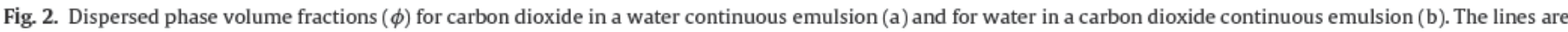

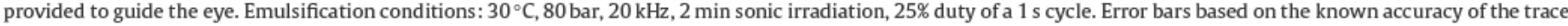
analysis techniques.
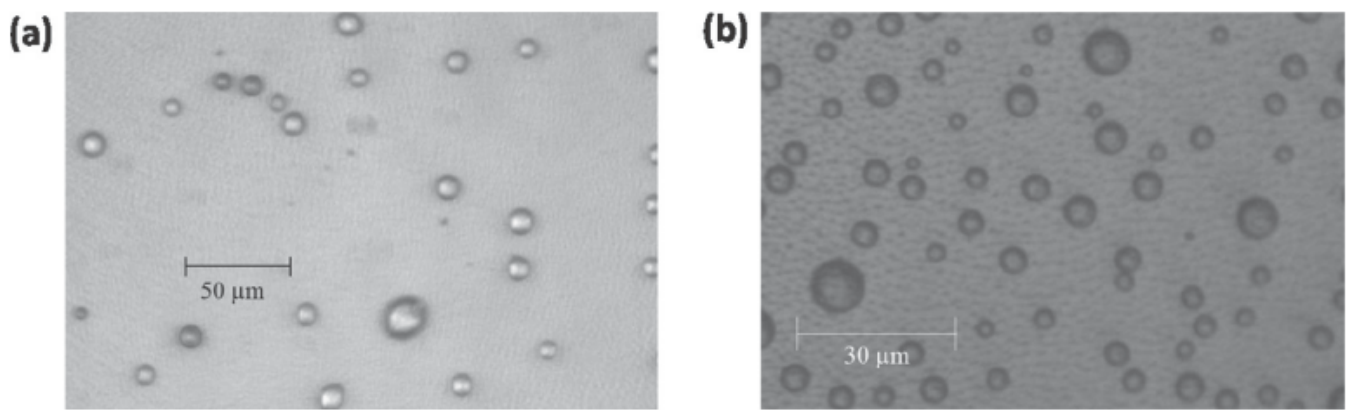

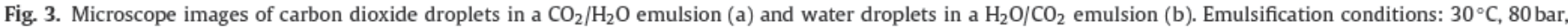
$0.6 \mathrm{~W} \mathrm{~cm}^{-3}, 20 \mathrm{kHz}, 2$ min sonic irradiation, $25 \%$ duty of a $1 \mathrm{~s}$ cycle.

ultrasound was pulsed $(0.5 \mathrm{~s}$ ON/2.0 s OFF) at power densities greater than $0.15 \mathrm{~W} \mathrm{~cm}^{-3}$.

Next, the volumes of the continuous phases $(\phi)$ were measured using an inert chemical tracer technique. Fig. 2 provides plots of the measured volume fractions as functions of ultrasound power density. Consistent with visual observation, the $\mathrm{CO}_{2} /$ water emulsion is not formed for power densities less than about $0.1 \mathrm{~W} \mathrm{~cm}^{-3}$. Interestingly, dilute (1-2 vol\%) water $/ \mathrm{CO}_{2}$ emulsions can be produced at power densities as low as about $0.05 \mathrm{~W} \mathrm{~cm}^{-3}$. For the $\mathrm{CO}_{2}$ /water emulsions, the measured dispersed phase volume fraction was nearly constant with increasing ultrasonic power density

Table 1

Visual observations of demulsification times, $\tau_{\text {observed }}$, for ultrasound emulsions containing dense carbon dioxide and water.

\begin{tabular}{lllll}
\hline Emulsion type & $P($ bar $)$ & $T\left({ }^{\circ} \mathrm{C}\right)$ & $\begin{array}{l}\text { Power density } \\
\left(\mathrm{W} \mathrm{cm}^{-3}\right)\end{array}$ & $\tau_{\text {observed }}{ }^{*}(\mathrm{~min})$ \\
\hline $\mathrm{H}_{2} \mathrm{O} / \mathrm{CO}_{2}$ & 65 & 20 & 0.05 & $<1$ \\
& & & 0.20 & 7 \\
& \multirow{2}{*}{80} & \multirow{2}{*}{30} & 0.30 & 9 \\
& & 0.05 & $<1$ \\
& & 0.20 & 7 \\
& & 0.30 & 9 \\
$\mathrm{CO}_{2} / \mathrm{H}_{2} \mathrm{O}$ & & 0.60 & 10 \\
& \multirow{2}{*}{65} & 20 & 0.05 & $\mathrm{NA}^{\mathrm{a}}$ \\
& & & 0.20 & 4 \\
& & 0.30 & 6 \\
& \multirow{2}{*}{80} & 30 & 0.05 & $\mathrm{NA}^{\mathrm{a}}$ \\
& & 0.20 & 15 \\
& & 0.30 & 15 \\
& & & 0.60 & 15
\end{tabular}

NA denotes "not applicable" and applies for demulsification times when no emulsion was formed. Emulsification conditions: $20 \mathrm{kHz}, 2$ min sonic irradiation, 25\% duty of a 1 s cycle.

- Estimated uncertainty of \pm 2 min or $\pm 20 \%$, whichever is less. beyond the $0.2 \mathrm{~W} \mathrm{~cm}^{-3}$ threshold. For the water $/ \mathrm{CO}_{2}$ emulsion, the volume fraction of water dispersed in the carbon dioxide phase increased slightly from about $5 \pm 1.5 \%$ to $9.0 \pm 2.0 \%$ when the power was increased from 0.3 to $1.3 \mathrm{~W} \mathrm{~cm}^{-3}$. At optimal power density conditions, power ultrasound dispersed approximately $4 \mathrm{vol} \%$ of carbon dioxide into water and up to $9 \mathrm{vol} \%$ of water into carbon dioxide (at $30^{\circ} \mathrm{C}$ and 80 bar).

\subsection{Droplet size measurements}

The next set of experiments aimed to measure the droplet diameters of the $\mathrm{CO}_{2}$ /water and water $/ \mathrm{CO}_{2}$ emulsions using a high pressure microreactor. Fig. 3 provides representative micrographs of $\mathrm{CO}_{2}$ droplets in a water continuous phase (Fig. 3a) and of water droplets in a $\mathrm{CO}_{2}$ continuous phase (Fig. 3b). At all times, the emulsion droplets were spherical in appearance and fully distinct, showing no signs of flocculation. Multiple images similar to Fig. 3 were analyzed and plotted as a histogram. As shown in Fig. 4, the resulting droplet size distributions were roughly log-normal, consistent with a randomized shearing process. The images in Fig. 3 and size distributions in Fig. 4 were analyzed carefully for systematic errors. The full details of the analysis are provided in the Supporting Information.

Typical examples of emulsion characteristics are summarized in Table 2, showing that the number averaged diameters were $5.2 \mu \mathrm{m}$ for the water $/ \mathrm{CO}_{2}$ emulsion and $12.3 \mu \mathrm{m}$ for the $\mathrm{CO}_{2} /$ water emulsion. These values compare well with diameters reported in the literature for surfactant-stabilized emulsions containing water and carbon dioxide phases [27,29,30]. Lee et al. [29] used perfluoropolyether ammonium carboxylate surfactants to stabilize water $/ \mathrm{scCO}_{2}$ emulsions, finding water droplets ranging in size from 3 to $10 \mu \mathrm{m}$. da Rocha et al. [27] used poly(ethylene oxide)$b$-poly(butylene oxide) as a surface active block co-polymer to 


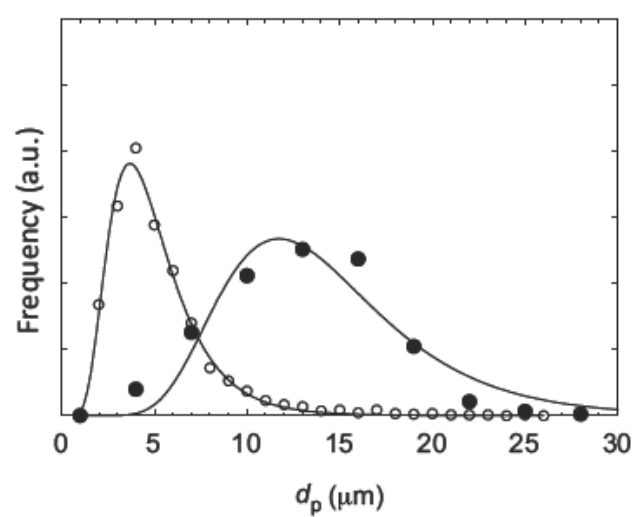

Fig. 4. Log normal size distributions of $\mathrm{CO}_{2}$ droplets in $\mathrm{CO}_{2} / \mathrm{H}_{2} \mathrm{O}$ emulsions (-) and $\mathrm{H}_{2} \mathrm{O}$ droplets in $\mathrm{H}_{2} \mathrm{O} / \mathrm{CO}_{2}$ emulsions (O). Emulsification conditions: $30^{\circ} \mathrm{C}, 80 \mathrm{bar}$, $0.6 \mathrm{~W} \mathrm{~cm}^{-3}, 20 \mathrm{kHz}, 2 \mathrm{~min}$ sonic irradiation, $25 \%$ duty of a $1 \mathrm{~s}$ cycle.

generate $\mathrm{scCO}_{2}$ /water emulsions with droplets ranging from 2 to $4 \mu \mathrm{m}$. Our results show that ultrasound without use of surfactants forms droplets on the larger end of this range. Since we have used much greater power densities than has been reported for generating the surfactant-stabilized emulsions, we surmise that the observation of larger droplets in the surfactant-free emulsion is consistent the importance of coagulation as a destabilization mechanism for droplets smaller than $5 \mu \mathrm{m}$.

\subsection{Emulsion stability analysis}

We next used the measured droplet sizes and volume fractions to estimate $\mathrm{CO}_{2} /$ water and water/ $\mathrm{CO}_{2}$ breaking times for the two common mechanisms of settling and coagulation. A principle aim was to reconcile measured emulsion characteristics with the measured breaking times provided in Table 1. Additionally, comparison between theory and experiment provides insight in the dominant breaking mechanism. For this first order analysis, volume-surface area average droplet diameters $\left(d_{32}\right)$ were used for calculating time constants, neglecting the effects of the full size distribution. We consider 2 mechanisms for emulsion breaking: (1) settling and (2) coagulation followed by settling. Settling refers to droplet rising (falling) through the surrounding continuous phase to re-join its original phase due to the effects of gravity. Coagulation is the process of droplet re-combination to form droplets with larger diameters, while conserving total mass. Settling rates increase monotonically with increasing droplet diameter whereas coagulation rates increase with decreasing droplet diameter. Therefore, a critical diameter exists at which coagulation is more rapid than settling. Here, we use simple methods to estimate time constants for these 2 processes to determine whether settling can explain emulsion breaking and/or whether time constants for coagulation are rapid enough that the effects of the coagulation process factor into observations of emulsion stability.

Settling time scales are determined by calculation of droplets terminal velocities (which we will assume they attain rapidly) in

Table 2

Averages of droplet distributions given in microns.

\begin{tabular}{lrrrr}
\hline Droplet type & $\left\langle d_{N}\right\rangle$ & $\left\langle d_{s}\right\rangle$ & $\left\langle d_{v}\right\rangle$ & $\left\langle d_{32}\right\rangle=d_{v}{ }^{3} / d_{s}{ }^{2}$ \\
\hline Water/carbon dioxide & 5.2 & 6.0 & 6.8 & 9.1 \\
Carbon dioxide/water & 12.3 & 13.2 & 13.8 & 15.1 \\
\hline
\end{tabular}

Emulsification conditions: $30^{\circ} \mathrm{C}, 80 \mathrm{bar}, 0.6 \mathrm{~W} \mathrm{~cm}^{-3}, 20 \mathrm{kHz}, 2$ min sonic irradiation, $25 \%$ duty of a $1 \mathrm{~s}$ cycle. Error bars based on the known accuracy of the trace analysis techniques. Notation: $d_{n}$ is the number-average droplet diameter; $d_{s}$ is the surface area average droplet diameter; $d_{v}$ is the volume averaged droplet diameter, and $d_{32}$ is the volume-area average diameter, termed the "Sauter" diameter. relation to the length scale over which droplets need to rise (fall) before joining their parent continuous phases. In our analysis of settling, we consider two cases: (1) unhindered settling in which droplet velocities are not affected by the presence of other droplets and (2) hindered settling which attempts to account for the reductions in droplet velocity caused by the presence of other droplets mutually rising (falling) in the same continuous phase. The simple relationship for the terminal velocity of a droplet undergoing settling unhindered by the presence of other droplets ( $U_{\text {unhindered }}$ ) is:

$U_{\text {unhindered }}=\frac{\left(2 g r^{2}\right)\left(\rho_{d}-\rho\right)}{9 \mu}$

where $r$ is the droplet radius $\left(r=d_{32} / 2\right), \mu$ is the continuous phase dynamic viscosity, $g$ is the gravitational constant $\left(9.81 \mathrm{~m} \mathrm{~s}^{-2}\right), \rho_{d}$ is the density of the dispersed phase, and $\rho$ is the density of the continuous phase. Table 3 provides the densities and viscosities used in this study. Pure fluid properties were used throughout; the effects of mutual solubility of the two fluids on these values of density and viscosity were assumed to be negligible. Using simple linear velocity arguments, Eq. (1) can be used to calculate a time constant for unhindered settling ( $\tau_{\text {unhindered }}$ ) given a settling path $(L)$ :

$\tau_{\text {unhindered }}=\frac{L}{U_{\text {unhindered }}}=\frac{L}{\left(\left(\left(2 g r^{2}\right) \times\left(\left|\rho_{d}-\rho\right|\right) / 9 \mu\right)\right)}$

Batchelor [57] developed a rigorous expression for droplet terminal velocity $\left(U_{\text {hindered }}\right)$ in a dilute emulsion ( $\left.<10 \mathrm{vol} \%\right)$ :

$\frac{U_{\text {hindered }}}{U_{\text {unhindered }}}=1-6.55 \phi_{d}$

which we use here as an estimate as the emulsion densities are in the range of applicability $\left(\phi_{\mathrm{H}_{2} \mathrm{O}} \approx 0.065\right.$ for the considered experimental conditions: $30^{\circ} \mathrm{C}, 80 \mathrm{bar}, 0.6 \mathrm{~W} \mathrm{~cm}{ }^{-3}, 20 \mathrm{kHz}, 2 \mathrm{~min}$ sonic irradiation, $25 \%$ duty of a 1 s cycle, see Fig. 2 b).

For coagulation, we applied Smoluchowski's theory [58] of "fast coagulation" which assumes that all droplet collisions are completely effective for re-combination. This limiting behavior is justified for surfactant-free emulsions since the energy barrier for droplet re-combination, the factor which prevents droplet collisions from being effective, should be negligible compared to thermal energy. The time scale for coagulation, $\tau_{\text {coagulation, }}$ is given by:

$\tau_{\text {coagulation }}=\left(\frac{\pi \mu}{k_{B} T}\right) \frac{r^{3}}{\phi_{d}}$

where $k_{B}$ is the Boltzmann constant, $\phi_{d}$ is the dispersed phase volume fraction (either $\mathrm{CO}_{2}$ or water), and $T$ is the temperature. Smoluchowski theory models droplet diffusion using Stokes-Einstein theory, which should be appropriate as a first approximation for the relatively dilute emulsions ( $<10 \mathrm{vol} \%$ dispersed phase) considered here.

Table 3

Physical properties used for calculation of emulsion breaking times.

\begin{tabular}{lc}
\hline Property $^{\mathrm{a}}$ & Value $^{\mathrm{b}}$ \\
\hline Carbon dioxide & 702 \\
Density $\left(\mathrm{kg} \mathrm{m}^{-3}\right)$ & $5.6 \times 10^{-5}$ \\
Viscosity $\left(\mathrm{kg} \mathrm{m}^{-1} \mathrm{~s}^{-1}\right)$ & \\
& \\
Water & 997 \\
Density $\left(\mathrm{kg} \mathrm{m}^{-3}\right)$ & $8.0 \times 10^{-4}$ \\
Viscosity $\left(\mathrm{kg} \mathrm{m}^{-1} \mathrm{~s}^{-1}\right)$ & \\
\hline
\end{tabular}

a All properties estimated at $30^{\circ} \mathrm{C}$ and 80 bar.

b NIST Thermophysical database [56] was used for estimation of pure fluid physical properties. 
Table 4

Calculated time constants, $\tau$, for the breaking of acoustically generated emulsions ${ }^{\mathrm{a}}$.

\begin{tabular}{|c|c|c|c|c|c|}
\hline Emulsion & $\left\langle d_{32}\right\rangle=d_{v}{ }^{3} / d_{s}{ }^{2}(\mu \mathrm{m})$ & Observed life time (min) & $\tau_{\text {unhindered }^{\mathrm{b}, \mathrm{c}}(\mathrm{min})}$ & $\tau_{\text {hindered }^{\mathrm{b}, \mathrm{d}}(\mathrm{min})}$ & $\tau_{\text {coagulation }}{ }^{\mathrm{e}}(\mathrm{min})$ \\
\hline Water/carbon dioxide & 9.1 & 10 & 7 & 12 & 1 \\
\hline Carbon dioxide/water & 15.1 & 15 & 36 & 49 & 107 \\
\hline
\end{tabular}

a Conditions: $30^{\circ} \mathrm{C}, 80 \mathrm{bar}, 0.6 \mathrm{~W} \mathrm{~cm}^{-3}, 20 \mathrm{kHz}, 2$ min sonic irradiation, $25 \%$ duty of a $1 \mathrm{~s}$ cycle.

b Settling times were calculated assuming a settling distance of $10 \mathrm{~cm}$.

c Calculated using Eq. (2).

d Calculated using Eqs. (2) and (3).

e Calculated using Eq. (4).

Eqs. (1)-(4) were used to estimate time constants for emulsion breaking. Table 4 summarizes the results obtained considering the following operating parameters: $30^{\circ} \mathrm{C}, 80 \mathrm{bar}, 0.6 \mathrm{~W} \mathrm{~cm}^{-3}, 20 \mathrm{kHz}$, 2 min sonic irradiation, $25 \%$ duty of a $1 \mathrm{~s}$ cycle. As a general observation, estimates for emulsion breaking time constants are uniformly larger for the $\mathrm{CO}_{2}$ /water emulsion compared to the water $/ \mathrm{CO}_{2}$ emulsion. Since other factors are nearly equal, we attribute the superior stability of the $\mathrm{CO}_{2}$ /water emulsions primarily to the 10 fold larger viscosity of the water continuous phase compared to the $\mathrm{CO}_{2}$ continuous phase. For water $/ \mathrm{CO}_{2}$ emulsions, the estimated $\tau_{\text {coagulation }}$ is much shorter than the observed stability time (1 min compared to $10 \mathrm{~min}$ ), suggesting that water droplet coagulation is an important demulsification mechanism. In addition, $\tau_{\text {hindered }}$ for the water $/ \mathrm{CO}_{2}$ emulsions is similar to the observed stability time (12 min compared to $10 \mathrm{~min}$ ), which support the assumption of a hindered settling mechanism for the demulsification. For the $\mathrm{CO}_{2}$ /water emulsions, $\tau_{\text {coagulation }}$ is much larger than the observed stability time (103 min compared to $15 \mathrm{~min}$ ), suggesting that coagulation plays only a minor role in $\mathrm{CO}_{2}$ /water emulsion breaking. In comparison, $\tau_{\text {hindered }}$ is much smaller than $\tau_{\text {coagulation }}$, consistent with hindered settling dominating $\mathrm{CO}_{2}$ /water emulsions breaking.

\subsection{Analysis of surface wave mechanisms}

We next sought to examine the ultrasound emulsification mechanism. Following the literature on ultrasound formation of oil/water emulsions, we considered two primary mechanisms [59-61]: (1) surface waves and (2) ultrasonic cavitation. These two mechanisms have been suggested [59-61] to be important for ultrasonic formation of oil/water emulsions and here we modify the physical theories for mixtures consisting of $\mathrm{CO}_{2}$ and water. This section discusses surface wave phenomena and Section 3.5 provides an analysis of ultrasonic cavitation.

Waves formed at a fluid-fluid interface under the influence of a sufficiently strong driving force can shed droplets to form mists and emulsions. Mechanistically, surface waves formed during sonication can become unstable, resulting in droplet formation when waves with a critical wavelength break off into the adjoining continuous phase. The critical wavelength therefore provides a useful scale for correlating droplet diameters. Rayleigh-Taylor capillary wave theory [62], which accounts for the effects of surface tension that governs the formation of new droplets, provides a good starting point. Peskin and Raco [63] performed a linear stability analysis of a fluid-fluid interfacial wave undergoing forced oscillatoins to determine that, to first order, the Rayleigh-Taylor capillary-wave theory could be used to determine the critically unstable wavelength, $\lambda$ :

$\frac{1}{\lambda}=\frac{1}{\pi}\left(\frac{\Delta \rho \omega^{2}}{4 \gamma}\right)^{1 / 3}$

where $\Delta \rho$ is the density difference between the continuous and dispersed phases (here $\mathrm{CO}_{2}$ and water), $\gamma$ is the interfacial tension, and $\omega$ is the driving frequency (always $20,000 \times 2 \pi$ in these experiments). For the $\mathrm{CO}_{2}$-water system at $30^{\circ} \mathrm{C}, 80 \mathrm{bar}, \Delta \rho$ is $295 \mathrm{~kg} \mathrm{~m}^{-3}, \gamma$ is $32.10^{-3} \mathrm{~N} \mathrm{~m}^{-1}$ [56,64]. Droplets formed by breakup of the interfacial waves have diameters which are on the order of $\lambda / 2$, leading to an estimated diameter of $\sim 50 \mu \mathrm{m}$ for droplets formed by waves at the carbon dioxide/water interface.

Although $50 \mu \mathrm{m}$ is larger than the droplet diameters observed in the dense $\mathrm{CO}_{2}$ / water emulsions by about an order of magnitude, the estimated size suggests that, in principle, surface waves can form a coarse pre-emulsion. In fact, interfacial waves were clearly visible during emulsification at power densities less than $0.05 \mathrm{~W} \mathrm{~cm}^{-3}$ (image provided in Supporting Information). The surface waves were likely present at higher power densities as well, but obscured by the dense emulsions. Moreover, the $50 \mu \mathrm{m}$ droplets predicted by Eq. (5) are consistent with the observation that sonication at $0.05 \mathrm{~W} \mathrm{~cm}^{-3}$ produced water $/ \mathrm{CO}_{2}$ emulsions which broke in $<1 \mathrm{~min}$ after termination of sonic irradiation (see Table 1 ).

Table 1 also indicates that sonication at $0.05 \mathrm{~W} \mathrm{~cm}^{-3}$ formed coarse water $/ \mathrm{CO}_{2}$ emulsions but not $\mathrm{CO}_{2} /$ water emulsions, an observation predicted by a more sophisticated stability analysis [65] than captured in Eq. (5). Specifically, Gopal [65] performed a stability analysis of surface wave formation to show that the denser phase (water, in this case) should form a narrow spike as it penetrates the less dense phase (i.e., $\mathrm{CO}_{2}$ ). The peak of the narrow spike is more likely to break off to form droplets due to its low stability. The waves of the less dense $\mathrm{CO}_{2}$ phase become blunted as they penetrate the water phase and they are therefore less likely to form droplets. Therefore, formation of coarse water $/ \mathrm{CO}_{2}$ emulsions - but not $\mathrm{CO}_{2}$ /water emulsions - is consistent with Gopal's stability theory [65].

\subsection{Analysis of cavitation mechanism}

Based on the quantitative and qualitative arguments outlined in Section 3.4, we deemed it likely that the surface wave mechanism is responsible for initial formation of coarse water droplets but unlikely responsible for formation of droplets $<10 \mu \mathrm{m}$. For formation of finer droplets, we considered ultrasonic cavitation. Sonication of reaction mixtures promotes both chemical and physical effects [66]; differentiating them can be a challenge, especially in multiphase reactors in which mass transfer effects can play a determining role [66]. Observations of ultrasound emulsions of $\mathrm{CO}_{2}$-water mixtures is consistent with the conclusion that the physical effects of ultrasonic cavitation persist at high pressures. We therefore sought to determine the potential importance of cavitation-induced sonochemistry for sonication of $\mathrm{CO}_{2}$-water mixtures.

Physically, cavitation can occur when [67]: (1) the tension placed on a liquid during the ultrasonic rarefaction cycle is sufficient to create a cavity in the liquid and (2) the ultrasonic and mass transfer conditions are appropriate for growth of the cavity to a critical size which (3) collapses adiabatically during an ultrasonic compression cycle, achieving temperatures $>1000 \mathrm{~K}$ and extreme local pressures [68]. If the collapse occurs near a liquid-liquid or liquid-solid interface, high velocity microjets are formed; these jets are responsible for cavitation damage, ultrasonic cleaning, particle dispersion, and emulsion formation [69]. The extreme temperatures of the collapsing bubbles can be sufficient to drive chemical 


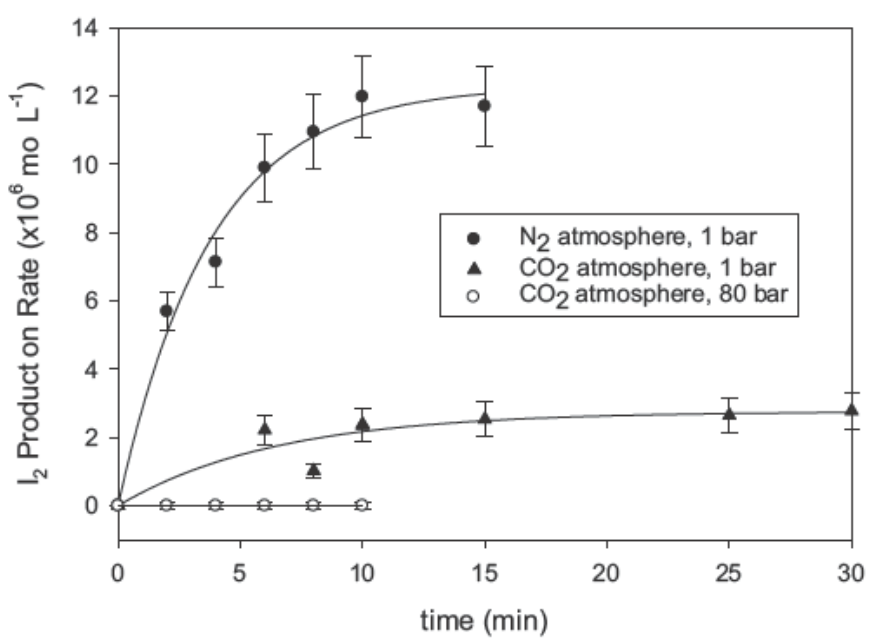

Fig. 5. Measured $I_{2}$ production rates measured under 1 bar of $N_{2}$ pressure; 1 bar of $\mathrm{CO}_{2}$ pressure, and 80 bar $\mathrm{CO}_{2}$ pressure.

reactions, a phenomenon termed sonochemistry. For example, radical reactions associated with pyrolysis conditions have been observed in a solution with a bulk temperature close to ambient [70].

Given the frequent convolution of physical and chemical effects of ultrasound, we turned to oxidation of $\mathrm{KI}$ as a mean to probe cavitation-induced sonochemistry in the dense $\mathrm{CO}_{2}$-water mixture. KI oxidation has become a standard way to calibrate the effectiveness of a sonochemical reactor at harnessing ultrasound for chemical reactivity [71,72]. When an aqueous KI solution is subjected to ultrasound, $\mathrm{I}^{-}$is oxidized by $\mathrm{OH}^{\bullet}$ liberated by sonolytic decomposition of water [73] to yield $I_{2}$. In the presence of excess $I^{-}, I_{2}$ forms a rapid equilibrium with $I_{3}^{-}$, which can be monitored by absorbance at $354 \mathrm{~nm}$ [71]. Although sonochemical reactions in dense and $\mathrm{scCO}_{2}$ have been the subject of recent studies $[74,75]$ and in water in contact with low-pressure $\mathrm{CO}_{2}$ [76], KI oxidation has not yet been evaluated in the presence of a dense or $\mathrm{scCO}_{2}$ phase. Given that ultrasound cavitation is a known emulsification mechanism in oil/water systems and that KI oxidation can be used to quantify some aspects of ultrasound cavitation, we investigated the KI oxidation reaction in the ultrasound water- $\mathrm{CO}_{2}$ environment.

In total, we performed KI oxidation experiments under 3 sets of conditions:(1) $\mathrm{N}_{2}$ gas pressure of $1 \mathrm{bar},(2) \mathrm{CO}_{2}$ gas pressure of $1 \mathrm{bar}$, and (3) dense $\mathrm{CO}_{2}$ pressure of 80 bar. Fig. 5 contains plots of the $I_{2}$ formation rate as a function of reaction time for these 3 conditions. A clear trend is evident; $I_{2}$ formation is highest under $\mathrm{N}_{2}$ conditions; is reduced by a factor of about 5 under low-pressure $\mathrm{CO}_{2}$ conditions; and is nearly completely suppressed to an estimated rate of $1 \times 10^{-7} \mathrm{~mol} \mathrm{~h}^{-1} \mathrm{~W}^{-1}$ under $\mathrm{CO}_{2}$ conditions. Our results are broadly consistent with the sparse literature on high-pressure sonochemistry [75]. At modest pressures ( $<10$ bar), experimental work has shown that increasing the over-pressure of a water-insoluble gas (e.g., $\mathrm{N}_{2}$ ) results in increased sonochemical yields [77] whereas the effects of over-pressurization with a water-soluble gas (e.g., $\left.\mathrm{CO}_{2}\right)$ have been to decrease yields [76]. Our work extends these data to the supercritical regime. From literature comparison, Kuijpers et al. [78] report that ultrasound can be used to initiate radical polymerization reactions in a solvent expanded by high-pressure $\mathrm{CO}_{2}$. On the other hand, van Iersel et al. [79] concluded on the basis of numerical simulations that sonochemical reactions were unlikely to occur in pure dense carbon dioxide, which is consistent with our work.

Based on the available literature and our own measurements, we conclude that sonication of the water- $\mathrm{CO}_{2}$ mixture leads to cavitation with collapse damped by $\mathrm{CO}_{2}$ that vaporizes into the bubble. Bubble collapse must be sufficiently violent to promote physical effects such as droplet formation, but sonochemical reactions are damped by the presence of the dense $\mathrm{CO}_{2}$ phase or the associated high concentration of dissolved carbonate species. Our own observations of the cavitation field during sonication support the hypothesis that the physical nature of cavitation changes in the high-pressure environment. During sonication and at any pressure, the camera field of view was turbid and did not yield useful images. Immediately following ultrasound termination, the turbidity decreased to the point that images could be obtained. At low pressures, a residual cloud of sub-millimeter-scale bubbles remained for several seconds after ultrasound was terminated. These bubbles were too small for our video equipment to resolve. At high pressures, a residual cloud of much larger $(\sim 5 \mathrm{~mm})$ bubbles would persist for a few seconds after ultrasound termination (see Supporting Information). We take the qualitative differences in the cavitation field at low and high pressure as further support of the shift of the nature of cavitation in the water- $\mathrm{CO}_{2}$ environment.

In the literature and specific to dense and $\mathrm{scCO}_{2}$-water systems, Goldfarb et al. [80] performed electrochemical reactions which supported the theory that sonication of carbon dioxide/water mixtures results in a phenomena termed "soft cavitation". Goldfarb et al, [80] found that the soft cavitation phenomenon in water/dense $\mathrm{CO}_{2}$ was capable of accelerating mass transfer in a diffusion controlled electrochemical reaction. Similarly, Cenci et al. [37] found that an aluminum foil placed in the vicinity of a sonochemical horn placed in a water- $\mathrm{scCO}_{2}$ solvent system became perforated-the aluminum foil test is a common way to examine physical effects of ultrasound [81]. Cushioned collapse is consistent with the observation that sonication of the $\mathrm{scCO}_{2}$-water mixture generates droplets on the order of $5-10 \mu \mathrm{m}$, whereas sonication of oil/water mixtures has been observed to generate much finer emulsions [61]. In fact, the dense $\mathrm{CO}_{2}$-water system has lower viscosity and (in the mutual absence of surfactants) lower surface tension than the oil/water mixtures [56], both factors which should promote formation of finer emulsions in the dense $\mathrm{CO}_{2}$-water mixture than oil-water mixtures [61]. The hypothesis of $\mathrm{CO}_{2}$-cushioned bubble collapse is therefore consistent with the observation of large dense $\mathrm{CO}_{2}$ and water droplet diameters than might be obtained under similar conditions for an oil-water system, despite the fact that the $\mathrm{CO}_{2}$ system has physical properties that would be expected to favor formation of finer emulsions.

Based on the emulsion characteristics and stability and the experiments and analysis of emulsification mechanism, we conclude that ultrasound emulsions consisting of dense $\mathrm{CO}_{2}$ and water proceeds via two steps: (1) formation of a coarse pre-emulsion consisting of $\sim 50 \mu \mathrm{m}$ droplets via surface wave break-up followed by (2) soft cavitation to form finer emulsions consisting of $<10 \mu \mathrm{m}$ droplets. As mentioned previously, this conclusion is consistent with the observation that water $/ \mathrm{CO}_{2}$ emulsions are formed at low power densities, whereas $\mathrm{CO}_{2}$ /water emulsions are not. Moreover, the two-step mechanism is consistent with the fact that the water $/ \mathrm{CO}_{2}$ emulsions are finer ( $\sim 9 \mu \mathrm{m}$ diameters $)$ and more dense (up to 9 vol\%) than $\mathrm{CO}_{2} /$ water emulsions ( $\sim 15 \mu \mathrm{m}$ diameters and about $4 \mathrm{vol} \%$ ). The formation of water $/ \mathrm{CO}_{2}$ pre-emulsions via surface waves provides more opportunities to produce finer emulsions via cavitation. Given that cavitation is likely related to formation of $\mathrm{CO}_{2}$-filled pockets, it is far more likely to occur in the water phase during periods in which the instantaneous local pressure falls below the $\mathrm{CO}_{2}$ saturation pressure. $\mathrm{CO}_{2}$ cavitation in the water phase will lead to formation of water micro-jets that form a spray of water droplets directed into the $\mathrm{CO}_{2}$ bulk phase. By contrast, $\mathrm{CO}_{2}$ droplets likely form due to entrainment into local turbulent structures [82]. Hence, the water droplets should be finer than the dense $\mathrm{CO}_{2}$ droplets and the water/ $/ \mathrm{CO}_{2}$ emulsion should be more 
concentrated than the $\mathrm{CO}_{2}$ /water emulsion-both of which are, in fact, consistent with observations.

\section{Engineering considerations}

The emulsion formation and emulsion characteristics studies provide sufficient information for an approximate energy efficiency calculation and to guide reactor optimization and scale-up. Table 5 summarizes the data inputs for the calculation. Energy efficiency is a crucial technological consideration for any process [83]. Despite some reports to the contrary [84], Walstra and Smulders [85] compiled emulsification data showing that ultrasound achieves higher energy dissipation rates than mechanical emulsification methods (including colloid mills, high-pressure homogenizers, and the "Ultra Torrex") and that ultrasound is more energy efficient at a given energy density. An energy analysis was performed for the ultrasound $\mathrm{CO}_{2} /$ water and water $/ \mathrm{CO}_{2}$ emulsions. Specifically, the minimum surface work required to form the emulsions was compared to the estimated required energy and found to correspond to an energy efficiency of $0.03 \%$, as described in the Supporting Information. The calculated emulsification efficiency is less than the $0.1 \%$ efficiency quoted by Walstra and Smulders [85] as a typical emulsification efficiency for oil-water systems. The difference in efficiency may be due to the much lower viscosity of the dense $\mathrm{CO}_{2}$ phase compared to oil phases; an energy inefficient reactor design; or the absence of surfactants in the ultrasound $\mathrm{CO}_{2}$ /water emulsions. In any event, the current reactor geometry has not yet been optimized and further work can realistically be expected to yield improved energy efficiency.

Scale-up of the ultrasound emulsification system would most likely be achieved in a flow-through system [86]. If a single continuous emulsion containing dense $\mathrm{CO}_{2}$ and water were desired, emulsification might be achieved using a flow-through $\mathrm{CO}_{2}$-water mixing tee with a nominal volumetric flow ratio of 20:1 (consistent with the densest emulsions observed here). The size of the mixing tee would be constrained by the requirement that the optimal horn-interface standoff distance should be approximately $2 \mathrm{~cm}$, as reported by Timko et al. [33] To achieve average residence times on the order of $100 \mathrm{~s}$ (the time required for ultrasound generation), the ultrasound tee could be associated with a larger reactor and used as a pump-around.

The emulsion stability analysis summarized in Table 4 indicates that the resulting dense $\mathrm{CO}_{2}$-water emulsion breaks by the combined action of coagulation and settling. A stable emulsion ( $\tau>100 \mathrm{~min}$ ) could be achieved if the dense $\mathrm{CO}_{2}$ droplet diameter could be reduced by another factor of 2-3 and stabilized to coagulation. Alternatively, kinetically stable and surfactant-free $\mathrm{CO}_{2}$ /water emulsions might be formed using a continuous process in which a series of droplets flow inside a tubing at a constant separation distance that prevents droplet coagulation. For an environmental application, $\mathrm{scCO}_{2}$ droplet stabilization could also be

Table 5

Data inputs for energy efficiency calculations.

\begin{tabular}{|c|c|}
\hline Property & Value \\
\hline$\phi_{\text {carbon dioxide }}$ & 0.04 \\
\hline$\phi_{\text {water }}$ & 0.09 \\
\hline$d_{32, \text { carbon dioxide }}(\mu \mathrm{m})$ & 15.1 \\
\hline$d_{32, \text { water }}(\mu \mathrm{m})$ & 9.1 \\
\hline Reactor volume $\left(\mathrm{cm}^{3}\right)$ & 87 \\
\hline Total surface area $\left(\mathrm{m}^{2}\right)$ & 3.4 \\
\hline Minimum work $(\mathrm{J})$ & 0.11 \\
\hline Power density $\left(\mathrm{W} \mathrm{cm}^{-3}\right)$ & 1.5 \\
\hline Formation time (s) & 10 \\
\hline Duty cycle (\%) & 25 \\
\hline Energy input $(\mathrm{J})$ & 340 \\
\hline
\end{tabular}

achieved using particles (Pickering emulsion) with balanced $\mathrm{CO}_{2}-$ philic/hydrophilic properties (e.g., Janus particles) [87].

\section{Conclusions}

Ultrasound has potential as a surfactant-free technology for producing emulsions consisting of a dense $\mathrm{CO}_{2}$ phase and water for a variety of chemicals and materials applications. In this work, we performed emulsion stability, characterization, and formation experiments and analysis. We found that $\mathrm{CO}_{2} /$ water emulsions had a dispersed phase content of approximately 4 vol\% dispersed phase content and an average droplet diameter of about $15 \mu \mathrm{m}$ whereas the water $/ \mathrm{CO}_{2}$ emulsion had up to $9 \mathrm{vol} \%$ dispersed phase content and average droplet diameters of $9 \mu \mathrm{m}$ range. The water $/ \mathrm{CO}_{2}$ emulsions broke in approximately $15 \mathrm{~min}$ and likely followed a coagulation/settling mechanism; the $\mathrm{CO}_{2}$ /water emulsions broke in about $10 \mathrm{~min}$, likely by a settling mechanism. Water $/ \mathrm{CO}_{2}$ emulsions likely formed via a two-step mechanism featuring surface wave break-up to form a coarse emulsion followed by $\mathrm{CO}_{2}$ cushioned cavitation to form finer emulsions. Engineering analysis suggests energy efficient (0.03\%) scale-up might be achieved in a carefully designed flow reactor.

\section{Acknowledgments}

We gratefully thank the U.S. Environmental Protection Agency Technology for a Sustainable Environment Program (Agreement No. R 826738-01-0) and the Cambridge University-Massachusetts Institute of Technology (MIT) Institute (CMI) for providing partial support for this research. Jefferson W. Tester (Cornell University) and Kenneth A. Smith (MIT) provided technical advice during the early stages of this work. MTT was supported as a Martin Family Fellow for portions of this work. ARM was supported by a Carl and Inez Weidenmiller Family Fellowship for portions of this work. Worcester Polytechnic Institute start-up funds provided travel support to help establish the collaboration.

\section{Appendix A. Supplementary data}

Supplementary data associated with this article can be found, in the online version, at http://dx.doi.org/10.1016/j.supflu.2015.10. 028.

\section{References}

[1] D.J. Cole-Hamilton, Homogeneous catalysis-new approaches to catalyst separation, recovery, and recycling, Science 299 (2003) 1702-1706.

[2] M.N. Timofeeva, Acid catalysis by heteropoly acids, Appl. Catal., A: Gen. 256 (2003) 19-35

[3] B.M. Bhanage, M. Arai, Catalyst product separation techniques in Heck reaction, Catal. Rev. Sci. Eng. 43 (2001) 315-344.

[4] R.A. Sheldon, Green solvents for sustainable organic synthesis: state of the art, Green Chem. 7 (2005) 267-278.

[5] J.N. Chheda, Y. Roman-Leshkov, J.A. Dumesic, Production of 5-hydroxymethylfurfural and furfural by dehydration of biomass-derived mono- and poly-saccharides, Green Chem. 9 (2007) 342-350.

[6] J.M. Campos-Martin, M.C. Capel-Sanchez, P. Perez-Presas, J.L.G. Fierro, Oxidative processes of desulfurization of liquid fuels, J. Chem. Technol. Biotechnol. 85 (2010) 879-890

[7] Y. Roman-Leshkov, J.N. Chheda, J.A. Dumesic, Phase modifiers promote efficient production of hydroxymethylfurfural from fructose, Science 312 (2006) 1933-1937.

[8] M. Araia, S. Fujitaa, M. Shirai, Multiphase catalytic reactions in/under dense phase $\mathrm{CO}_{2}$, J. Supercrit. Fluids 47 (2009) 351-356.

[9] Y. Medina-Gonzalez, S. Camy, J.S. Condoret, $\mathrm{ScCO}_{2}$ /green solvents: biphasic promising systems for cleaner chemicals manufacturing, ACS Sustainable Chem. Eng. 2 (2014) 2623-2636.

[10] P. Pollet, R.J. Hart, C.A. Eckert, C.L. Liotta, Organic aqueous tunable solvents (OATS): a vehicle for coupling reactions and separations, Acc. Chem. Res. 43 (2010) 1237-1245 
[11] B.M. Bhanage, Y. Ikushima, M. Shirai, M. Arai, Multiphase catalysis using water-soluble metal complexes in supercritical carbon dioxide, Chem. Commun. (1999) 1277-1278.

[12] M.B. King, A. Mubarak, J.D. Kim, T.R. Bott, The mutual solubilities of wate with supercritical and liquid carbon-dioxide, J. Supercrit. Fluids 5 (1992) 296-302.

[13] C.A. Eckert, D. Bush, J.S. Brown, C.L. Liotta, Tuning solvents for sustainable technology, Ind. Eng. Chem. Res. 39 (2000) 4615-4621.

[14] V. Arunajatesan, K.A. Wilson, B. Subramaniam, Pressure-tuning the effective diffusivity of near-critical reaction mixtures in mesoporous catalysts, Ind. Eng. Chem. Res. 42 (2003) 2639-2643.

[15] T. Funazukuri, C.Y. Kong, S. Kagei, Binary diffusion coefficients in supercritica fluids: recent progress in measurements and correlations for binary diffusion coefficients, J. Supercrit. Fluids 38 (2006) 201-210.

[16] I. Medina, Determination of diffusion coefficients for supercritical fluids, J. Chromatogr. A 1250 (2012) 124-140.

[17] K. Brudi, N. Dahmen, H. Schmieder, Partition coefficients of organic substances in two-phase mixtures of water and carbon dioxide at pressures of 8 to $30 \mathrm{MPa}$ and temperatures of 313 to $333 \mathrm{~K}$, J. Supercrit. Fluids 9 (1996) $146-151$.

[18] M.T. Timko, B.F. Nicholson, J.I. Steinfeld, K.A. Smith, J.W. Tester, Partition coefficients of organic solutes between supercritical carbon dioxide and water: experimental measurements and empirical correlations, J. Chem. Eng. Data 49 (2004) 768-778.

[19] K.D. Wagner, K. Brudi, N. Dahmen, H. Schmieder, Partition coefficients of aromatic organic substances in two-phase mixtures of water and carbon dioxide at pressures from 8 to $30 \mathrm{MPa}$ and at temperatures of 313 to $333 \mathrm{~K}$. Part II, J. Supercrit. Fluids 15 (1999) 109-116.

[20] J.D. Holmes, K.J. Ziegler, M. Audriani, C.T. Lee, P.A. Bhargava, D.C. Steytler, K.P. Johnston, Buffering the aqueous phase $\mathrm{pH}$ in water-in- $\mathrm{CO}_{2}$ microemulsions, J. Phys. Chem. B 103 (1999) 5703-5711.

[21] C. Roosen, M. Ansorge-Schumacher, T. Mang, W. Leitner, L. Greiner, Gaining pH-control in water/carbon dioxide biphasic systems, Green Chem. 9 (2007) $455-458$.

[22] K.P. Johnston, S.R.P. da Rocha, Colloids in supercritical fluids over the last 20 years and future directions, J. Supercrit. Fluids 47 (2009) 523-530.

[23] J.L. Dickson, P.G. Smith, V.V. Dhanuka, V. Srinivasan, M.T. Stone, P.J. Rossky, J.A. Behles, J.S. Keiper, B. Xu, C. Johnson, J.M. DeSimone, K.P. Johnston, Interfacial properties of fluorocarbon and hydrocarbon phosphate surfactants at the water- $\mathrm{CO}_{2}$ interface, Ind. Eng. Chem. Res. 44 (2005) 1370-1380.

[24] J.L. Dickson, B.P. Binks, K.P. Johnston, Stabilization of carbon dioxide-in-water emulsions with silica nanoparticles, Langmuir 20 (2004) 7976-7983.

[25] J.L. Dickson, C. Ortiz-Estrada, J.E. Alvarado, H.S. Hwang, I.C. Sanchez, G. Luna-Barcenas, K.T. Lim, K.P. Johnston, Critical flocculation density of dilute water-in- $\mathrm{CO}_{2}$ emulsions stabilized with block copolymers, J. Colloid Interface Sci. 272 (2004) 444-456.

[26] J.L. Dickson, P.A. Psathas, B. Salinas, C. Ortiz-Estrada, G. Luna-Barcenas, H.S. Hwang, K.T. Lim, K.P. Johnston, Formation and growth of water-in- $\mathrm{CO}_{2}$ miniemulsions, Langmuir 19 (2003) 4895-4904.

[27] S.R.P. da Rocha, P.A. Psathas, E. Klein, K.P. Johnston, Concentrated $\mathrm{CO}_{2}$-in-water emulsions with nonionic polymeric surfactants, J. Colloid Interface Sci. 239 (2001) 241-253.

[28] P.A. Psathas, S.R.P. da Rocha, C.T. Lee, K.P. Johnston, K.T. Lim, S. Webber, Water-in-carbon dioxide emulsions with poly(dimethylsiloxane)-based block copolymer ionomers, Ind. Eng. Chem. Res. 39 (2000) 2655-2664.

[29] C.T. Lee, P.A. Psathas, K.P. Johnston, J. deGrazia, T.W. Randolph, Water-in-carbon dioxide emulsions: formation and stability, Langmuir 15 (1999) 6781-6791.

[30] M.L. Oneill, M.Z. Yates, K.L. Harrison, K.P. Johnston, D.A. Canelas, D.E. Betts, J.M. DeSimone, S.P. Wilkinson, Emulsion stabilization and flocculation in $\mathrm{CO}_{2}$ 1. Turbidimetry and tensiometry, Macromolecules 30 (1997) 5050-5059

[31] M.Z. Yates, M.L. Oneill, K.P. Johnston, S. Webber, D.A. Canelas, D.E. Betts, J.M. DeSimone, Emulsion stabilization and flocculation in $\mathrm{CO}_{2}$. 2. Dynamic light scattering, Macromolecules 30 (1997) 5060-5067.

[32] J. Eastoe, B.M.H. Cazelles, D.C. Steytler, J.D. Holmes, A.R. Pitt, T.J. Wear, R.K. Heenan, Water-in- $\mathrm{CO}_{2}$ microemulsions studied by small-angle neutron scattering, Langmuir 13 (1997) 6980-6984.

[33] M.T. Timko, A.J. Allen, R.L. Danheiser, J.I. Steinfeld, K.A. Smith, J.W. Tester, Improved conversion and selectivity of a Diels-Alder cycloaddition by use of emulsions of carbon dioxide and water, Ind. Eng. Chem. Res. 45 (2006) 1594-1603

[34] S.A. Nolen, J. Lu, J.S. Brown, P. Pollet, B.C. Eason, K.N. Griffith, R. Glaser, D. Bush, D.R. Lamb, C.L. Liotta, C.A. Eckert, G.F. Thiele, K.A. Bartels, Olefin epoxidations using supercritical carbon dioxide and hydrogen peroxide without added metallic catalysts or peroxy acids, Ind. Eng. Chem. Res. 41 (2002) 316-323.

[35] M.T. Timko, K.A. Smith, R.L. Danheiser, J.I. Steinfeld, J.W. Tester, Reaction rate in ultrasonic emulsions of dense carbon dioxide and water, AIChE J. 52 (2006) 1127-1141.

[36] M.T. Timko, J.M. Diffendal, J.W. Tester, K.A. Smith, W.A. Peters, R.L. Danheiser, J.I. Steinfeld, Ultrasonic emulsification of liquid, near-critical carbon dioxide-water biphasic mixtures for acceleration of a hydrolysis reaction, J. Phys. Chem. A 107 (2003) 5503-5507.

[37] S.M. Cenci, L.R. Cox, G.A. Leeke, Ultrasound-induced emulsification of subcritical carbon dioxide/water with and without surfactant as a strategy for enhanced mass transport, Ultrason. Sonochem. 21 (2014) 401-408.
[38] M. Jikei, S. Saitoh, H. Yasuda, H. Itoh, M. Sone, M. Kakimoto, H. Yoshida, Electrochemical polymerization of pyrrole in supercritical carbon dioxide-in-water emulsion, Polymer 47 (2006) 1547-1554.

[39] S.M. Cenci, L.R. Cox, G.A. Leeke, Ultrasound-induced $\mathrm{CO}_{2} / \mathrm{H}_{2} \mathrm{O}$ emulsions as a medium for clean product formation and separation: the barbier reaction as a synthetic example, ACS Sustainable Chem. Eng. 2 (2014) 1280-1288.

[40] A.H. Liu, R. Ma, M. Zhang, L.N. He, In situ acidic carbon dioxide/water system for selective oxybromination of electron-rich aromatics catalyzed by copper bromide, Catal. Today 194 (2012) 38-43.

[41] R.J. Bonilla, B.R. James, P.G. Jessop, Colloid-catalysed arene hydrogenation in aqueous/supercritical fluid biphasic media, Chem. Commun. (2000) 941-942.

[42] M. Chatterjee, T. Ishizaka, H. Kawanami, Hydrogenation of 5-hydroxymethylfurfural in supercritical carbon dioxide-water: a tunable approach to dimethylfuran selectivity, Green Chem. 16 (2014) 1543-1551.

[43] M. McCarthy, H. Stemmer, W. Leitner, Catalysis in inverted supercritical $\mathrm{CO}_{2}$ /aqueous biphasic media, Green Chem. 4 (2002) 501-504.

[44] J.S. Luterbacher, J.W. Tester, L.P. Walker, Two-temperature stage biphasic $\mathrm{CO}_{2}-\mathrm{H}_{2} \mathrm{O}$ pretreatment of lignocellulosic biomass at high solid loadings, Biotechnol. Bioeng. 109 (2012) 1499-1507.

[45] T.M. Rueda, J.G. Serna, M.J.C. Alonso, Direct production of $\mathrm{H}_{2} \mathrm{O}_{2}$ from $\mathrm{H}-2$ and $\mathrm{O}-2$ in a biphasic $\mathrm{H}_{2} \mathrm{O} / \mathrm{scCO}_{2}$ ) system over a Pd/C catalyst: optimization of reaction conditions, J. Supercrit. Fluids 61 (2012) 119-125.

[46] S.K. Karmee, L. Greiner, A. Kraynov, T.E. Muller, B. Niemeijer, W. Leitner, Nanoparticle catalysed oxidation of sulfides to sulfones by in situ generated $\mathrm{H}_{2} \mathrm{O}_{2}$ in supercritical carbon dioxide/water biphasic medium, Chem. Commun. 46 (2010) 6705-6707.

[47] X. Dong, D. Potter, C. Erkey, Synthesis of CuS nanoparticles in water-in-carbon dioxide microemulsions, Ind. Eng. Chem. Res. 41 (2002) 4489-4493.

[48] C. Chang, Q.L. Zhou, J.Q. Guo, Q.C. Yu, Supercritical $\mathrm{CO}_{2}$ dissolution and mass transfer in low-permeability sandstone: effect of concentration difference in water-flood experiments, Int. J. Greenhouse Gas Control 28 (2014) 328-342.

[49] J. Eastoe, A. Paul, A. Downer, D.C. Steytler, E. Rumsey, Effects of fluorocarbon surfactant chain structure on stability of water-in-carbon dioxide microemulsions. Links between aqueous surface tension and microemulsion stability, Langmuir 18 (2002) 3014-3017.

[50] T. Sakai, Surfactant-free emulsions, Curr. Opin. Colloid Interface Sci. 13 (2008) 228-235.

[51] M.T. Timko, Acoustic Emulsions of Liquid, Near-Critical Carbon Dioxide and Water: Application to Synthetic Chemistry Through Reaction Engineering, Massachusetts Institute of Technology, Cambridge MA, 2004.

[52] S. Marre, A. Adamo, S. Basak, C. Aymonier, K.F. Jensen, Design and packaging of microreactors for high pressure and high temperature applications, Ind. Eng. Chem. Res. 49 (2010) 11310-11320.

[53] S. Marre, Y. Roig, C. Aymonier, Supercritical microfluidics: opportunities in flow-through chemistry and materials science, J. Supercrit. Fluids 66 (2012) 251-264.

[54] D.M. Ratner, E.R. Murphy, M. Jhunjhunwala, D.A. Snyder, K.F. Jensen, P.H. Seeberger, Microreactor-based reaction optimization in organic chemistry glycosylation as a challenge, Chem. Commun. (2005) 578-580.

[55] E.R. Murphy, T. Inoue, H.R. Sahoo, N. Zaborenko, K.F. Jensen, Solder-based chip-to-tube and chip-to-chip packaging for microfluidic devices, Lab Chip 7 (2007) 1309-1314.

[56] R. Span, W. Wagner, A New Equation of State for Carbon Dioxide Covering the Fluid Region from the Triple-Point Temperature to $1100 \mathrm{~K}$ at Pressures up to 800 MPa, J. Phys. Chem. Ref. Data 25 (1996) 1509-1596.

[57] G.K. Batchelor, Sedimentation in a dilute dispersion of spheres, J. Fluid Mech. 52 (1972) 245-268

[58] M.v. Smoluchowski, Versuch einer mathematischen Theorie der Koagulationskinetik kolloider Lösungen, Zeitschrift fuer physikalische Chemie 92 (1917) 129-168

[59] M. Li, H. Fogler, Acoustic emulsification. Part 2. Breakup of the large primary oil droplets in a water medium, J. Fluid Mech. 88 (1978) 513-528.

[60] M. Li, H. Fogler, Acoustic emulsification. Part 1. The instability of the oil-water interface to form the initial droplets, J. Fluid Mech. 88 (1978) 499-511.

[61] J.R. Canselier, H. Delmas, A.M. Wilhelm, B. Abismail, Ultrasound emulsification-an overview, J. Dispersion Sci. Technol. 23 (2002) 333-349.

[62] G. Taylor, The instability of liquid surfaces when accelerated in a direction perpendicular to their planes. I, in: Proceedings of the Royal Society of London A: Mathematical, Physical and Engineering Sciences, The Royal Society, 1950, pp. 192-196.

[63] R.L. Peskin, R.J. Raco, Ultrasonic atomization of liquids, J. Acoust. Soc. Am. 35 (1963) 1378-1381

[64] B.-S. Chun, G.T. Wilkinson, Interfacial tension in high-pressure carbon dioxide mixtures, Ind. Eng. Chem. Res. 34 (1995) 4371-4377.

[65] E.S.R. Gopal, Principles of emulsion formation, in: ShermanF P. (Ed.), Emulsion Science, Academic Press, New York, NY, 1968, pp. 4-72.

[66] L.C. Hagenson, L. Doraiswamy, Comparison of the effects of ultrasound and mechanical agitation on a reacting solid-liquid system, Chem. Eng. Sci. 53 (1998) 131-148

[67] T.G. Leighton, 2-Cavitation inception and fluid dynamics, in: T.G. Leighton (Ed.), The Acoustic Bubble, Academic Press, Boston, MA, 1994, pp. 67-128.

[68] E.B. Flint, K.S. Suslick, The temperature of cavitation, Science 253 (1991) 1397-1399.

[69] C.E. Brennen, Cavitation and Bubble Dynamics, Oxford University Press, New York, NY, 1995 
[70] N.H. Ince, G. Tezcanli, R.K. Belen, I.G. Apikyan, Ultrasound as a catalyzer of aqueous reaction systems: the state of the art and environmental applications, Appl. Catal., B: Environ. 29 (2001) 167-176.

[71] S. Koda, T. Kimura, T. Kondo, H. Mitome, A standard method to calibrate sonochemical efficiency of an individual reaction system, Ultrason. Sonochem. 10 (2003) 149-156.

[72] J.D. Seymour, H.C. Wallace, R.B. Gupta, Sonochemical reactions at $640 \mathrm{kHz}$ using an efficient reactor. Oxidation of potassium iodide, Ultrason. Sonochem. 4 (1997) 289-293.

[73] P. Cintas, J.L. Luche, Green chemistry-the sonochemical approach, Green Chem. 1 (1999) 115-125

[74] M.E. Kemmere, M.W.A. Kuijpers, R.M.H. Prickaerts, J.T.E. Keurentjes, A novel process for ultrasound-induced radical polymerization in $\mathrm{CO}_{2}$-expanded fluids, Macromol. Mater. Eng. 290 (2005) 302-310.

[75] M.M. van Iersel, R. Mettin, N.E. Benes, D. Schwarzer, J.T.F. Keurentjes, Sound-driven fluid dynamics in pressurized carbon dioxide, J. Chem. Phys. 133 (2010), 044304-1 through 044304-4.

[76] H. Harada, Y. Ono, M. Oda, Decrease in the rate of sonochemical oxidation with introduction of $\mathrm{CO}_{2}$, Jpn. J. Appl. Phys. 53 (2014), 07KE10-1 through 07KE10-2.

[77] J. Rooze, E.V. Rebrov, J.C. Schouten, J.T.F. Keurentjes, Dissolved gas and ultrasonic cavitation-a review, Ultrason. Sonochem. 20 (2013) 1-11.

[78] M.W.A. Kuijpers, D. van Eck, M.F. Kemmere, J.T.F. Keurentjes, Cavitation-induced reactions in high-pressure carbon dioxide, Science 298 (2002) 1969-1971.
[79] M.M. van Iersel, J. Cornel, N.E. Benes, J.T.F. Keurentjes, Inhibition of nonlinear acoustic cavitation dynamics in liquid $\mathrm{CO}_{2}$, J. Chem. Phys. 126 (2007), 064508-1 through 064508-8.

[80] D.L. Goldfarb, H.R. Corti, F. Marken, R.G. Compton, High-pressure sonoelectrochemistry in aqueous solution: Soft cavitation under $\mathrm{CO}_{2}$, J. Phys. Chem. A 102 (1998) 8888-8893.

[81] V. Saez, A. Frias-Ferrer, J. Iniesta, J. Gonzalez-Garcia, A. Aldaz, E. Riera, Chacterization of a $20 \mathrm{kHz}$ sonoreactor. Part I: analysis of mechanical effects by classical and numerical methods, Ultrason. Sonochem. 12 (2005) 59-65.

[82] H.C. Starritt, F.A. Duck, V.F. Humphrey, Forces acting in the direction of propagation in pulsed ultrasound fields, Phys. Med. Biol. 36 (1991) $1465-1474$

[83] J.C. Warner, A.S. Cannon, K.M. Dye, Green chemistry, Environ. Impact Assess Rev. 24 (2004) 775-799.

[84] Y.-F. Maa, C.C. Hsu, Performance of sonication and microfluidization for liquid-liquid emulsification, Pharm. Dev. Technol. 4 (1999) 233-240.

[85] P. Walstra, P. Smulders, Emulsion formation, in: B.P. Binks (Ed.), Modern Aspects of Emulsion Science, The Royal Society of Chemistry, Cambridge, UK, 2006, pp. 56-99.

[86] E. Loranger, M. Paquin, C. Daneault, B. Chabot, Comparative study of sonochemical effects in an ultrasonic bath and in a large-scale flow-through sonoreactor, Chem. Eng. J. 178 (2011) 359-365.

[87] A. Perro, F. Meunier, V. Schmitt, S. Ravaine, Production of large quantities of "Janus" nanoparticles using wax-in-water emulsions, Colloids Surf., A: Physicochem. Eng. Aspects 332 (2009) 57-62. 